Running head: REFLECTING CRITICALLY ON RJ THEORY

[This is an Accepted Manuscript of an article published by Taylor \& Francis in

RESTORATIVE JUSTICE: AN INTERNATIONAL JOURNAL on December 2013

(Volume 1, Issue 3, ) available online: http://www.tandfonline.com/ Article DOI:

10.5235/20504721.1.3.311.]

\title{
A window on relationships: reflecting critically on a current restorative justice theory ${ }^{1}$
}

Dorothy Vaandering ${ }^{2}$

Assistant Professor, Memorial University of Newfoundland (Canada), dvaandering@mun.ca

\begin{abstract}
Inherent in the task of theorising is a responsibility for ongoing critical reflection of the ideas presented (Steele, 2010). To that end, this article responds to the invitation extended by McCold and Wachtel to examine the conceptual theory of restorative justice they first presented in 2003 and which continues to be promoted globally. One particular aspect of their theory, the Social Discipline Window, is examined. Drawing on a qualitative, critical case study conducted in schools in Ontario, Canada, the article illustrates: (a) how unexamined theory can be problematic and promote practice that counters the principles of restorative justice; and (b) how people's lives can be impacted by power dynamics inherent in the theory presented (Woolford, 2009). In response, a revised Relationship Window is presented along with examples of how it can affect practice that is more consistently aligned with the philosophical foundations of restorative justice.
\end{abstract}

\section{A. Introduction}

Restorative justice (rj) $)^{3}$ practices continue to grow across the disciplines of criminology, social work, education and beyond. In response to the realisation that theory lags behind

\footnotetext{
1 The content of this paper was first presented at the International Institute for Restorative Justice World Conference, October 2010, Hull (England).

${ }^{2}$ This research was supported by the Social Sciences and Humanities Research Council of Canada and Ontario Graduate Scholarship.
} 
practice (Braithwaite 2006; Morrison \& Ahmed, 2006; Sherman \& Strang, 2007), researchers are digging deep to explore philosophical contexts and develop theoretical frameworks to explain, shape and strengthen its practices (Elliott, 2011; Gavrielides, 2007; Llewellyn, 2012; McCold \& Wachtel, 2003; Sullivan \& Tifft, 2006; Vaandering, 2011; Woolford, 2009; Zehr, 2005). Such work is important as 'a sharp view on restorative justice is needed to promote its sound implementation and future policy making' (Aertsen et al., 2013: 4). Inherent in the task of theorising, however, is a responsibility for ongoing critical reflection on the ideas presented (Foucault, 1980; IshShalom, 2009; Steele, 2010) as their intrinsic features when promoted render them 'susceptible to public misinterpretation and vulnerable to political abuse' (Ish-Shalom, 2009). In a field where rj remains a 'deeply contested concept' (Johnstone \& Van Ness, 2007), this is particularly important.

To that end, this article is a response to the invitation extended by McCold \& Wachtel (2003) to examine the conceptual theory of rj that they developed, which continues to be promoted regularly and globally in the work and accompanying literature of the International Institute for Restorative Practices (IIRP) (Costello, Wachtel \& Wachtel, 2010, 2012; Wachtel, 2013) and by those educated there. In particular, I examine the Social Discipline Window, one aspect of their three-part framework. ${ }^{4}$ Situated within my own experience, first as an educator, and more recently as a researcher examining $\mathrm{rj}$ in educational settings in Ontario, Canada, I discover what Woolford (2009) calls 'the hopefulness of rj ethos often com[ing] up against the crass political realities of conflict' and school life. I illustrate (a) how unexamined theory can be problematic and promote practice that counters the philosophical principles of rj; and (b) how the lives of people touched by such theory can be negatively impacted by the 'power dynamics of both the actual practices of $\mathrm{rj}$, as well as in the broader collective and social-structural circumstances in which rj is implemented' (Woolford, 2009: 57). In response, I present a revised theoretical component, a Social Relationship Window that echoes the recent work of Llewellyn (2012) and Ross (2012) and provide examples of how it could affect

\footnotetext{
${ }^{3}$ Using lowercase rj as an abbreviation is very intentional. Though grammar protocol would suggest that abbreviations be capitalised, by capitalising it, the term becomes a proper noun, a name of particular thing/being. When restorative justice becomes a proper noun it is at risk of becoming a particular approach, practice or strategy instead of a more general 'way of being'.

${ }^{4}$ See McCold \& Wachtel (2003) for a complete description of their conceptual theory.
} 
practice that is more consistently aligned with the philosophical foundations of $\mathrm{rj}$ as described by Bianchi (1994), Elliott (2011), Pranis, Stuart and Wedge (2003), Sullivan and Tifft (2005), and Zehr (2005).

\section{B. The Invitation}

In proposing their conceptual theory, McCold and Wachtel (2003) invite social scientists to test its 'validity for explaining and predicting the effects of restorative justice practices' (p. 1). However, other than research carried out by the IIRP itself, a search of current academic literature does not reveal any direct responses to their proposed theory. In a qualitative critical case study I conducted in a public elementary school in Ontario, Canada in 2008 that examined factors affecting the implementation and sustainability of rj in schools, evidence informing the validity of McCold and Wachtel's theory of rj emerged. In particular, the influence of and manner in which educators engaged with the Social Discipline Window surfaced as a contributing factor to inconsistent and ineffective implementation of $\mathrm{rj}$ and its ability to nurture the relational school cultures desired.

The IIRP, located in Pennsylvania, USA, was established in 1999 and has gone on to become an accredited graduate school with affiliate offices across the world. Beyond examining and providing training for restorative practices in formal judicial contexts, it promotes the use of proactive and reactive restorative practices for people involved in education, social work, counselling, youth services, and workplace and faith communities. In that role it has trained and influenced many people worldwide in the principles and practices of rj for schools, myself included. Central to their vision and approach is what McCold and Wachtel (2003) identify as 'a conceptual theory of rj' that 'provides the framework for a comprehensive answer to the how, what and who of the restorative justice paradigm' (p. 3). It includes the Social Discipline Window (Figure 1), one of three distinct structures in the theory. ${ }^{5}$

\section{[Figure 1-Insert near here]}

\footnotetext{
5 The other two conceptual structures include Stakeholder Roles and Restorative Practices Typology. The three are described as 'distinct but related conceptual structures ... that explain the how, what and who of restorative justice theory' (McCold \& Wachtel, 2003: 1). See Wachtel (2013) for a current, complete description of the framework in which the IIRP is grounded.
} 
This widely distributed diagram and view is designed to encourage educators to think beyond a punitive-permissive response to inappropriate student behaviour to a restorative, authoritative response where adults work together WITH students in a more engaged and relational manner.

[The Window] describes four basic approaches to maintaining social norms and behavioural boundaries. The four are represented as different combinations of high or low control and high or low support. The restorative domain combines both high control and high support and is characterised by doing things with people, rather than to them or for them (Wachtel, 2013: 3).

Clear limit-setting and diligent enforcement of behavioural standards and lax or non-existent regulation of behaviour characterise low social control. Active assistance and concern for well-being characterize high social support. Lack of encouragement and minimal provision for physical and emotional needs characterise low social support ... The punitive approach, with high control and low support, is also called retributive. It tends to stigmatise people, indelibly marking them with a negative label. The permissive approach, with low control and high support, is also called rehabilitative and tends to protect people from experiencing the consequences of their wrongdoing. Low control and low support are simply neglectful, an approach characterised by indifference and passivity. (McCold \& Wachtel, 2003: 1, 2).

This framework is a significant aspect of the IIRP, as evidenced by its presence in the promotional materials, publications and course/workshop content it distributes. It is used to support and explain its approach and thus provide assurance of its credibility. However, in the qualitative research I conducted in 2008, I found that upon returning to their schools and classrooms after training by IIRP facilitators that was grounded in this Social Discipline Window, educators are generally enthused and committed to doing what they can to engage with students. However, many fall back on or continue to use 
punitive-permissive responses to student behaviour, undermining $\mathrm{rj}$ principles they believe they are committed to implementing (Vaandering, 2009).

Given this response and the prominence the Social Discipline Window holds in training, a careful examination of the theory is warranted. To begin, two things are important to note: first, though the Social Discipline Window is presented as part of a 'conceptual theory' of rj, at most this theory is an explanation of how the IIRP approach works. It is lacking as a conceptual theory as it fails to address theories of justice underlying the practices. Second and connected to this, the Social Discipline Window is an adaptation of a theory put forth by Glaser (1964/1969), as Wachtel identifies in his early work (1999b, 2009), for describing effective practices of parole officers. Grounded here, the Social Discipline Window does not engage in conceptual understandings of rj. I will expand on the significance of both of these in what follows.

\section{Research Background}

Prior to becoming a researcher, I was an educator in primary and elementary schools, intrigued by and committed to peacemaking and conflict resolution programs. I asserted that student learning was directly affected by their ability to socialise and deal with conflicts. During that journey, I was introduced to McCold and Wachtel's (2003) theory and was especially intrigued by the Social Discipline Window. This simple diagram, from my practitioner perspective at the time, held the key to understanding the studentteacher relationship, as well as the student-student relationship. The Window and the practical direction provided by the IIRP (Wachtel, 1999a) in the form of an introductory article became my companions as I journeyed through each day in the classroom and school, impacting not only my relationships, but also my pedagogy and curriculum. Intrigued by the changes that took place and the hope it gave me as a teacher, I eventually engaged in graduate studies and research that I trusted would inform and strengthen the implementation and sustainability of rj principles and practices for schools. This required a careful examination of my own experience and allowed me to observe and reflect on the experience of others committed to rj.

The lens I chose to employ for this examination was provided by educational theorists committed to transformative teaching and learning, as I believed rj held the potential for 
educational transformation. In particular, I drew on Paulo Freire (2000) and bell hooks (1994, 2003), who modelled for me the significance of interrogating education using critical theory. Central to critical theory is the use of questions such as: Where does a particular education practice/theory come from? What is its frame of reference? And whose interests are served by it? Central also was the need for the responses to result in action that would lead to the well-being of all people (Kincheloe \& McLaren, 2005). As such, critical theory seeks to make hope practical (Giroux, 1988; Williams, 1980). This combination of critique, action and hope I trusted would open up my understanding of $\mathrm{rj}$ so that I might be able to encourage effective implementation and sustainability of $\mathrm{rj}$ in education more broadly. And it did. However, the process was difficult and the answers not easy to accept.

In the context of this paper, it is important to identify that I am using critical theory as a normative theory that allows for an examination and discussion about the values and value preferences of McCold and Wachtel's (2003) 'conceptual' theory that includes the Social Discipline Window. As such it deals with what ought to be (Viotti \& Kauppi, 1987). McCold and Wachtel's invitation, I recognise, is most likely intended for social scientists to validate their work empirically, identifying what is (Viotti \& Kauppi, 1987). The study that I conducted and draw on for this paper was a qualitative study that examined the experiences of two schools committed to implementing rj, one of which employed the services of the IIRP. Within that school, I explored the experience of fourteen educators who had received one to three days of training. Such a small sample does not produce empirical evidence from which generalisations can be made; however, it does produce a depth of insight from the experiences of a few that can then be used to raise questions about the foundational concepts of the theory in a way that a large empirical study cannot (Patton, 2002; Merriam, 2009). In this way, the study gives a glimpse into what is for the purpose of better understanding what ought to be, which then ultimately informs the implications and legitimacy of McCold and Wachtel's theory of rj. The particular research contexts that resulted in the ideas developed and reported on here were my own experiences as a teacher and parent of primary/elementary school-aged youth (autoethnography), as well as the experiences of an elementary school (JK-8), situated in a rural town community in Southern Ontario, Canada, where the adults in the school, students and interested parents from the community had all received training in rj 
by certified trainers from the IIRP. Qualitative, narrative case study methodology led me to interview fourteen of the 39 educators individually for approximately 45 minutes each about their interpretations and practice of rj for education. (All were invited, but many were reluctant and gave a rationale that they were not suitable participants for the research as they did not use restorative practices in their classrooms because their students were well behaved.) Of those interviewed, three agreed to have me observe them in their daily practice over a six-week period-one administrator and two teachers. Both individually and collectively, these participants provided a significant contribution to a clearer understanding of $\mathrm{rj}$ in education when viewed through the questions posed by critical theory. For this article, I refer briefly to key instances that reflect the participants' understanding of the Social Discipline Window and then focus my attention on how this Window provides a springboard for a Relationship Window that provides a broader perspective. $^{6}$

\section{The Experience of Implementing the Social Discipline Window-Four incidents}

I relate four incidents beginning with my own personal engagement with the Social Discipline Window as a grade three teacher. Prior to providing these details, it is necessary to point out that each occurs in a social context where an understanding of justice as 'right-order' is dominant, rather than justice as 'inherent rights' where the wellbeing of all is encouraged (Vaandering, 2011; Wolterstorff, 2008). In education, justice as 'right-order' has resulted in schools 'traditionally adopt[ing] a quasi-judicial approach to the management of student misconduct, modelled on existing western criminal justice systems' (Thorsborne \& Vinegrad, 2003). This identification of and distinction in perspectives of justice is significant for understanding how people respond to each other as human beings. As contemporary rj has come out of the judicial context, an emphasis on identifying right and wrong of an individual's behaviour and control often becomes the focus. However, when examining the roots of rj, a broader, more primary concept of justice becomes apparent, one where the worth and well-being of all people are emphasised (Bianchi, 1994; Llewellyn \& Howse, 1998; Wolterstorff, 2008; Zehr, 2005) and relationship and engagement become the focus (Llewellyn, 2012; Morrison, 2012;

\footnotetext{
${ }^{6}$ For details on in-depth findings of the study, see Vaandering (2009).
} 
Ross, 2012). With this in mind, the reason for each of the following incidents, which will be elaborated on in the next section of the paper, becomes clear.

1. As a teacher, I read and re-read, examined again and again, the different components of the Social Discipline Window (Wachtel, 1999a). High control of wrongdoing and high support of the individual person was what I aimed to provide to my students. When students did not respond to the expectations I set out for them, I would question whether I was clear enough in setting limits and whether I was providing enough support for them. Most often by adding to one or the other, or a bit to both, students' behaviours changed. If they did not, I assured myself that I was providing the correct balance, and they were not interested in working WITH me. As a result, for their well-being and the well-being of those around them, I would move into the TO box or the FOR box, but always with an invitation to return to the WITH box if they were interested. It all made sense.

Or did it?

After describing the principles and practice of rj to a colleague, she responded with, 'it still seems like all you're doing is trying to manage your students. It's all about you being in control of them.' I stopped short. My intrigue with rj was challenged. What was my intention in using rj? Was it to better control my students so my job would be easier? Was it for their well-being? What was rj anyway? Whose interests were really being served? Had I really left the punitive-permissive continuum as the model implied would happen if I just provided high support and high control (Wachtel, 1999a)?

2. My initial understanding of the Social Discipline Window is mirrored in the explanation of it by the administrator to the students in her school when she went to each class with a Social Discipline Window poster, after they had received a refresher training session by IIRP personnel three years subsequent to their first. She said to the students in each class:

We want to be in the WITH box because we like kids and believe this is important. I try not to ask, Why? However, if rj doesn't work, we move into the 
TO box. ... we tell you the rules, if you break them, you are reminded. If you still do it, we'll talk more. If you still do it, we'll get all sides. If that doesn't help, we'll need to move to the TO box.

Two things are worth questioning at this point. First, what is the source of both the administrator and myself feeling justified in moving out of the restorative quadrant into the retributive quadrant when it is clear that the theoretical framework indicates that 'people are happier ... and more likely to make positive changes when those in authority do things with them, rather than to them or for them?' (Wachtel, 2013: 3, emphasis in original). Second, the administrator's comment came after being involved with rj for four years. She was passionate about $\mathrm{rj}$, excited that her school was implementing $\mathrm{rj}$, and confident that after several years of engaging with the approach the culture in the school was changing. Though there is no doubt that changes had occurred in the school, the question arises as to why the lived experience with a rj approach over time did not result in the administrator recognising that moving into the retributive box was returning to the punitive-permissive continuum.

3. To further demonstrate the return to a retributive response, the administrator's perspective is illustrated in an incident that occurred when a student had caused some damage to a boys' bathroom by throwing wet paper towel balls at the ceiling. In an effort to identify who was responsible, the administrator announced the incident over the intercom for the whole school to hear, enlisting student and teacher help. Though the administrator may not have consciously understood this request for help to be a disguised use of public shaming and surveillance of both adults and youth, her power position and decision to make this a public, whole-school concern illustrates a use of power that is firmly planted in the retributive quadrant of the Window. This was further solidified when half an hour after the first announcement a second was given:

I am pleased to announce that we have caught the culprit and he is sitting in the office with me right now. Justice will be served. 
Later, when I asked about the response, she stated that she was operating out of both the TO and WITH box:

We explained to them what the problem was, what they were doing and why it was an issue and the importance of it ... there was also a consequence and there was no warning in it. Kids know ... it's vandalism. It's not telling the truth because they knew what they were doing and they kept doing it.

Though the administrator had defined rj earlier as 'a process for resolution of issues that is fair and gives everyone a voice', in this instance she did not recognise that the student had not been given a voice in either the establishment of the school rules or his explanation for his actions. She did not notice that she returned to the quasi-judicial school structure (Thorsborne \& Vinegrad, 2003) that rj seeks to replace when she used the terms 'culprit' and 'justice will be served'. As Christie (2013) indicates, the use of names and terms led her to 'conclude and close the process where we ought to start' ( $\mathrm{p}$. 17).

4. Finally, in interviewing fourteen educators in the school about their perspectives on and experiences with $\mathrm{rj}$, a theme emerged: they expressed a significant aspect of rj to be allowing students voice, but ultimately as the teachers they are in charge and responsible for disciplining individual student behaviour which requires that they establish the bottom line. This perspective is encapsulated in the words of one teacher who, when asked about using rj with a student who was not participating in class activity as asked, stated that rj was not appropriate:

That's when you need to be firm with the kid and say, 'what you've done is unacceptable. I don't want to talk about it. You know yourself it is ridiculous' ... [rj] is just something that you use ... as a strategy for bigger problems. This is 
between the boy and me, and I want him to stop behaving like a fool and he knows it.

Again, this response and others similar to it indicate that teachers maintain or revert to an authoritarian, punitive approach, even when they commit to rj and have visual reminders in the form of posters around them all the time.

A punitive, authoritarian approach is defined by McCold and Wachtel (2003) as a place of high control of wrongdoing and low, nurturing support of the individual student. In each of the four examples given, when faced with students not complying with set-out expectations, the adult felt justified in dictating what was to happen without providing a space for the student's voice. Why is it that educators fully committed to rj principles and practices have no qualms about or cannot recognise when they are acting out of their positions of power and doing things TO their students, often for their own convenience, even to the point of name-calling (culprit, fool)?

Because of the centrality of the Social Discipline Window to the training provided, its visibility in the schools (posters) working to implement rj practices, and educators' references to the distinctions amongst TO, FOR, NOT and WITH responses, a careful analysis of its components is warranted.

\section{E. The Influence of the Social Discipline Window}

In defining rj, McCold and Wachtel (2003) explain that 'it focuses on repairing harm done to people and relationships rather than punishing offenders' and that 'justice requires the healing of harm as much as possible' (p. 1). The Social Discipline Window has come out of this foundation as a means of moving away from the perceived effectiveness of punishment that is grounded in the belief that the more one is punished, the less likely one is to do it again. The intention of the Window is instead to embody the belief that the stronger the relationship, the less likely it is that people will act inappropriately towards each other (IIRP, 2012).

The key components of the Window that are intended to bring this to life are the vertical (control) and horizontal (support) axes, which create four quadrants that outline the 
choices one has for responding to harm done as described above. The origins of this matrix are important to note in terms of what contributes to it becoming distorted by proponents of rj in educational settings. McCold and Wachtel (2003) draw on the work of Glaser, who in 1964 published a book entitled The effectiveness of a prison and parole system and five years later published an abridged version. In analysing the practices of parole officers, Glaser develops a typology that describes four 'polar styles' of officer performance based on their reliance on combinations of high or low levels of control and assistance - the paternal (high control; high assistance); the punitive (high control; low assistance); welfare (low control; high assistance); and passive (low control; low assistance). The similarities between this typology and the Social Discipline Window are obvious. Given that the IIRP began as a school (CFS Buxton) for young offenders and youth recently imprisoned, it is also clear why McCold and Wachtel would draw on this work. However, the people being addressed are those who have caused harm to others and those working with them are charged with helping them transition from being incarcerated to living responsibly in society. The significance of control in this context is understood as surveillance, restriction and punishment (Glaser, 1964: 432). Assistance is understood as material aid, referral, counselling and mediation. The relationship between those providing control and assistance and those receiving it, is influenced greatly by power. In modifying the typology, McCold and Wachtel find it useful for understanding effective interaction between adults in roles of authority and youth who cause harm. However, they end up emphasising the power difference between parties engaged in $\mathrm{rj}$ as well as emphasising the role of 'offender' in their theoretical framework of practice, as revealed when Wachtel states that 'the fundamental underlying hypothesis of restorative practices is that "human beings are happier, more cooperative and productive, and more likely to make positive changes in their behaviour when those in positions of authority do things with them, rather than to them or for them", (Wachtel, 2013: 3, italics in original; bold added). This contradicts the emphasis of others (Christi, 1977; Sherman \& Strang, 2003; Zehr, 2002) who indicate that victims are of special concern in rj. It is also highly problematic when such a theory is presented in contexts such as education that have entirely different purposes and goals from the traditional judicial system where contemporary rj initiatives began. In these early days of rj, such critical reflection is necessary if co-optation of $\mathrm{rj}$ through institutional structures is to be avoided (Morris, 
1998). Ultimately, the Social Discipline Window is problematic because it is not rooted in the philosophical foundation of $\mathrm{rj}$ that indicates that people are relational, worthy human beings whose well-being is diminished or nurtured through relationships (Bianchi, 1994; Llewellyn \& Howse, 1998; Pranis, Stuart \& Wedge, 2003; Wolterstorff, 2008; Zehr, 2005).

As theory is developing to gain a better understanding of rj principles and practices, the subtleties of language must be acknowledged as being conveyors of power that can be oppressive or supportive. Though the Window was developed to provide a metaphor and structure for communicating a summary of intention that begins to influence and challenge the predominant use of adversarial justice, it is important to examine how this use of language impacts understanding and practice. What follows is an overview of the language used to describe the Social Discipline Window and how this seems to be interpreted by educators who are committed to practising $\mathrm{rj}$ in their educational environments.

Over time, McCold and Wachtel have come to place the Social Discipline Window on a foundation shared by other proponents in the field, who find its strength in principles that highlight people and relationships (Morrison, 2007; Pranis, Stuart \& Wedge, 2003; Sullivan \& Tifft, 2006). However, in their description of the Window, these perspectives are overshadowed by terms such as authority, regulation of behaviour, maintaining social order, enforcement of behavioural standards and social control (McCold \& Wachtel, 2003; Wachtel, 2009; Wachtel, 2013). Examining this shift using questions arising from critical theory, such as where are rj practices coming from?, what frame of reference is being employed?, whose interests are being served?, it is disconcerting to realise how a language of dominance which perpetuates hegemonic environments has taken precedence over the intended desire to strengthen relationships. This shift is not surprising given the fact that 'Western societies have relied on punishment ... to discipline those who misbehave or commit crimes', as McCold and Wachtel (2003: 1) themselves acknowledge. And most of us who consider ourselves proponents of rj are part of this Western context.

It is important to recognise the strength of dominant social influences if the desire of $\mathrm{rj}$ proponents is to shift paradigms as Zehr (2005) encourages Without this awareness, the juxtaposition of terms such as behaviour and maintaining social order with concepts of 
relationship and people results in confusion and discrepancies amongst those seeking to implement rj practices. To address this, it is important to reflect critically and look through the different concepts to their roots. In doing this it becomes apparent that different perspectives of justice are being referenced and used. Language highlighting behaviour and control defines justice as right-order; language that speaks of relationship defines justice as 'inherent rights' (Wolterstorff, 2008). In essence, the first is narrowly understood in the context of the Western judicial system and reinforces a perspective of people as objects to be managed and controlled; the second is a broad perspective that speaks of social justice and people as humans where the well-being of all humanity is sought (see Vaandering, 2009, 2011, for a full discussion).

The Social Discipline Window in its use of language and focus on behaviour, reinforces justice as 'right-order', which fits with its origin in Glaser's (1964) work. Beginning with the name of the Window, the term discipline is problematic. Definitions in a wide variety of dictionaries clearly point to its current use as a means of punishment, enforcement of rules and training for compliance. Lost is it etymological perspective connected to teaching and learning (www.dictionary.com). As a result, the Window sends a message that $\mathrm{rj}$ focuses on changing the behaviour of those who have caused harm. The needs of those who have been harmed and those who care about both parties are not part of the Window. Though rj began as a means for those who have been harmed and are often left out of the picture to have a voice and be involved in seeking resolution (Zehr, 2005), this theoretical Window encourages educators to use rj to respond primarily to the one causing harm, which would then indirectly address the needs of the one harmed.

The axes also contribute to emphasising the behaviour of those causing harm. The vertical axis focuses on the need to control, set limits and provide discipline by one who is in authority over others. The horizontal axis focuses on the need to provide support in the form of encouragement and nurturing by one who is in the position of knowing what is acceptable. This is grounded in Glaser's (1969) work and is not far from his definitions of assistance and control. It also embodies Wachtel's (2013) notion that 'people are happier when those in positions of authority do things with them, rather than to them or for them' (p. 3, italics in original, bold added). The ability to provide assistance and advice or curb behaviour through control is a position in which one has authority to 'fix' 
another. ${ }^{7}$ The WITH quadrant of the Window created through the use of high support and high control provided by the adult is nothing more than another explicit mechanism for controlling or manipulating behaviour. The term with implies a reciprocal relationship that those of us in control like to imagine is occurring. However, the Social Discipline Window does not allow for youth to provide high control or high support for the adult. Thus the WITH quadrant is not restorative or relational as it ultimately serves the needs of the authority only. As long as the actions represented in the axes cannot be shared or administered by all involved in a particular situation, the Window does not express the foundational elements of $\mathrm{rj}$ and actually perpetuates adversarial, hegemonic social structures.

This illustrates how language of dominance is able to seep in and reinforce a hegemonic society that marginalises and manipulates some of its members and works against the very intention of rj. This is not an easy pill to swallow. As a member of this dominant social segment, I am involved in rj because I desire desperately to work for equity and honouring the well-being of all humanity. Yet, I am discovering that the very tools I believed were helping are actually perpetuating what I am working against. Those of us who are promoting rj practices through the use of the Social Discipline Window must wake up to these discrepancies before the system we are 'trying to change' and those we are 'trying to help' rise up and point this out, seriously discrediting the foundation of rj itself.

The task of educators is complex and difficult as they are constantly engaged with people of different personalities, abilities and attitudes. Often struggling to meet the needs of their students, they are eager to listen when they are presented with options that will increase their effectiveness as a teacher for the nurturance of their students. When $\mathrm{rj}$ is presented as such, though perhaps sceptical initially, many teachers can relate to the Social Discipline Window and quite willingly embrace its structure as something that 'is common sense' and helpful for analysing and structuring their current practice. However, though $\mathrm{rj}$ is presented as a means for working with students in a restorative, relational manner, the explanation of its theory sends educators a very different message. The hidden point underlying the explicit relational intention described verbally is that $\mathrm{rj}$ is a

\footnotetext{
${ }^{7}$ This idea can also be traced to Rawls's (1999) perspective of 'justice as fairness' where social and economic inequality is acceptable only if attached to an office open to all or if the inequality is seen to be to the greatest benefit to the least advantaged (difference principle).
} 
means for educators to maintain social discipline, that they are in control of wrongdoing and limit-setting, that they can support and provide assistance to those lacking in some way-that their students can be manipulated. They hear that rj will help them manage student behaviour and that working WITH students is for the purpose of regulation and social order, not relationship. Herein, I propose, lies the reason for many educators falling back on or continuing to use punitive-permissive responses to student behaviour in spite of their intention to be relational and restorative after participating in a rj professional development experience.

Given that the root of rj lies in an integrated, relational world and life view promoted since ancient times through indigenous and spiritual traditions (Bianchi, 1994; Braithwaite, 1989; Pranis, Stuart \& Wedge, 2003; Zehr, 2005), the Social Discipline Window, in its emphasis on controlling wrongdoing and supporting 'right doing', steps away from rj principles by promoting a response to behaviour, rather than relationship. When rj is limited to issues of management and discipline, it inadvertently gets redirected to answering questions about rules, blame and punishment. In order to redirect thinking so that questions of harm done, the needs of those hurt, and repair of harm are addressed, concepts of relationship must be highlighted. Morrison (2012) solidifies this in her discussion of $r j$ as a form of social engagement rather than social control.

In a time and place where a judicial understanding of justice is firmly embedded and promoted in society that is intent on maintaining social discipline and order (Aertsen et al., 2013), the design of the Window is not surprising. It takes intense effort and ongoing alertness to initiate and advance a paradigm shift. It takes a mass of people to create the momentum needed to shift social perceptions. McCold and Wachtel (2003) are working to create this mass by articulating what they call a conceptual framework that promotes the use of rj principles and practices in all kinds of daily interactions besides the judicial system. However, their proposed theory is grounded in assumptions of justice rather than a foundation that examines concepts of justice. If authentic growth towards a paradigm shift is to occur, our perspectives and perceptions need to be examined constantly.

As critical theory's purpose is to initiate action, I respond to this critique with a proposal for a 'Relationship Window' in hopes that it will better reflect the essence of rj, which seeks to honour the inherent worth of all people and prevent the perpetuation of the punitive-permissive paradigm in schools. 


\section{F. A Window on Relationship}

Bianchi (1994) and Zehr's (1990, 2005) early theoretical exploration of rj engages with concepts of right relationship as being foundational for its understanding. Since then, theorists such as Howse and Llewellyn (1998), Llewellyn (2012) and Morrison (2012), as well as advocates such as Ross (2012) and Pranis (2007), have been putting forth explicit relational theories in which to ground rj. Building on this work, I suggest that a renovated Window can inform and illuminate the relational essence of rj. The basic design of the Social Discipline Window can be helpful. As a matrix, each of the four quadrants clearly identifies the results of varied responses given for which the terms TO (punitive), FOR (permissive), NOT (neglectful) and WITH (restorative) serve as apt descriptions. Changing the axes and the name of the Window, however, creates a very different and much more effective framework for thinking about and practising $\mathrm{rj}$.

Focusing on relationship amongst people and their environments invites users of the revised Window to reflect on interpersonal interactions first and foremost, which can include individual relationships that harm others. Like the Social Discipline Window, this occurs when two continuums are created and combined where each indicates high and low levels of engagement. In the renovated Window (Figure 2), however, the combination of the axes unpacks different types of relationships by using a vertical axis that is identified as 'expectations' for being human (where expectation includes accountability) and a horizontal axis that is identified as the 'support' one gives for being human.

[Figure 2-Insert near here]

The four quadrants that result identify interactions as either diminishing or nurturing one's inherent worth as a human being. This perspective of humanity is foundational to the broader concept of justice, as Bianchi (1994), Pranis, Stuart and Wedge (2003) and Zehr (2005) put forth as being the ultimate goal of rj-that of justice being understood as honouring the inherent worth of all, where people meet with the intent of fulfilling 'their vocation of becoming more fully human' (Freire, 2000). 
Specifically then, when people provide each other with high support and high expectations and accountability they treat each other as subjects, as humans, and relate WITH each other. Buber (1958: 24-25) explores this in his famous I-Thou and I-It relational orientations. Here, as humans we strive for relationships amongst each other where $I$ am understood in relation to You and vice versa. I-It involves distancing, where we separate ourselves from the other. Freire (2000) identifies this in his call for humanisation and states that 'No one can be authentically human while he prevents others from being so' (p. 69). The reciprocal nature of relationships is central to our ability to thrive. By combining a high level of expectation for the other and a low level of support, a hierarchical power relationship results. Disagreement, dominance and disruption characterise the relationship, as people are turned into objects that are acted upon so that they contribute to what the giver wants. The relationship is characterised by what is done TO another. High support and low expectations result in unhealthy interactions as well. Though it may begin well, in time the relationship deteriorates as people are seen as objects of need who also fulfil the giver's need to be needed. The relationship is characterised by what is done FOR another. Combining no support with no expectations results in a non-existent relationship or an extreme form of objectification. This relationship is characterised by what is NOT done-neglect of relationship. In the latter three responses, it is important to notice that harm is perpetuated, not repaired. When these quadrants are entered into, one is working against the paradigm shift needed for rj. It is also important to note that expectation and support can be given and received by anyone of any age, not just by an adult to a student as in the Social Discipline Window.

Another way of thinking about this Relationship Window is to use Simon's (1991) selfesteem terms, lovable and capable, as axes (Figure 3). If one is seen as NOT lovable or capable, they are neglected and ignored. If they are capable but not lovable, their skills are used to benefit the other. If they are lovable but not capable, they are used for the other's comfort. Only when I engage with someone believing that they are lovable and capable can I support and encourage them to be who they are becoming, and only here am I nurtured to be more fully human myself.

\section{[insert Figure 3 near here]}


Kohn (2005) identifies with this restorative quadrant as a place of unconditional love, where unconditional teaching and learning occurs - it doesn't matter what you say or do, I am still going to love you AND hold you accountable to be all you can be. The other three quadrants represent places of conditional acceptance, teaching and learning. In this regard, it becomes clear that if we are committed to honouring one another as human beings, it is not acceptable to move to any of the other three quadrants, as I first believed was possible in using the Social Discipline Window. Glasser (1985), not to be confused with Glaser (1964) as does occur at times, identifies the importance of maintaining a supportive role as a teacher and uses the terms with, for and to in his discourse differently from the Social Discipline Window, as he states:

Warmth and care are done with students, not to or for them ... If students reject warmth and care, they do so because they do not believe it is sincere. (p. 244)

He encourages educators to continue to offer warmth and care until the student is convinced of the sincerity of commitment. Glasser's work is grounded in the understanding that 'it is impossible to control another human being. If we wish to influence people then we need to create a satisfying relationship with them and, indeed, a satisfying environment in the school' (William Glasser International Institute, 2013). Though Glasser's work is grounded in individualism and rationalism rather than the social, interconnected, relational foundation of rj, his emphasis on the need to be sincere and consistent is helpful in highlighting the problem the Social Discipline Window has created in perpetuating the thought that adults can control youth.

A Relationship Window grounded in the principles of rj provides the framework that Morrison (2007) identifies as necessary for schools that are looking for a way to embed responses to behaviour in the broader context of relationship, as "many of the problems encountered in a typical school day are frequently misdiagnosed if not viewed through a relational lens and an exploration of factors contributing to relationship breakdown' (p. 348). This framework also allows for the organic growth of a relational school culture where participants in school communities explore together the fundamental principles of 
living in community so that a growth towards humanisation occurs. This common commitment from people within the school is critical for its growth and development (Glasser, 1985).

Finally the Relationship Window is also supported by contemporary educational research (Kohn, 2005; Morrison, 2007; Noddings, 2005; Palmer, 1998; Van Maanen, 2002), which calls clearly for the foundational role of relationship, care and trust in school cultures to be developed so that conducive learning environments can be nurtured and democratic citizenship can be encouraged. The perspectives and foundation that these researchers, in addition to Buber (1958), Freire (2000), Glasser (1985), Kohn (2005) and Simon (1991), provide reveal a contrasting foundation to that of Glaser (1964), whom McCold and Wachtel (2003) draw on, one that is much more conducive to understanding all youth and adults in the context of education and social development.

\section{G. An example}

Beyond the theoretical foundation that the Window on relationship provides, what would it look like in a school committed to rj practices? In an effort to put theory into practice, the following fictional narrative, using personal experience and the examples provided in the research I conducted, provides an example. Though it cannot stand alone in terms of supporting educators seeking to abandon a punitive approach, it can challenge them to critically reflect on how their use of language might be nuanced and politically saturated. In my personal experience such reflection moved me beyond blind acceptance of 'expert' knowledge and served as an impetus for significant change. The example is set up as an explanation for students, but a variation of the same presentation is required for the adults in the school community, as the shift in thinking for adults cannot be assumed. Adults will need to commit to living this out in their relationships with each other before or while expecting the students to engage with it meaningfully, as it is critical that students see this modelled for them each moment they are at school.

As a school we are committed to living together in relationship in such a way that everyone is honoured and supported as a human being who is using and 
discovering their unique gifts that contribute to the wonder of life. This Relationship Window will remind us of this commitment we make to each other.

\section{[Insert Figure 4 near here]}

The Window shows us that this won't always be easy. Sometimes we'll forget that we are human and we'll treat ourselves and each other as objects instead. We might think we aren't good enough or others aren't worth anything. This will show in what we do and how we interact with each other. At our best we will 'support' each other and 'expect' each other to be all that we can be. When we do this we live WITH each other as human beings. If we only support each other but don't expect each other to be human, then we treat one another like a stuffed toy-an object that we do things FOR so we feel good about ourselves. If we expect lots from each other but don't support each other, then we turn each other into machines and do things TO another so that we get what we want. If we don't support or expect anything from each other, we ignore each other and treat each other like dirt - as if they don't exist so we do NOT have to care for them. When we treat each other or ourselves like toys, machines, or dirt, we need to remind each other that we're human or we'll never become the people we could be.

An example of what could happen when things go wrong: Imagine that one of

you has vandalised the bathroom by writing graffiti on the wall. In such a situation, we will use the Relationship Window to guide us in working WITH you to remind you that in the vandalism you forgot that your actions impacted others' ability to be human. You have ignored other people's need for a clean facility, treating them like dirt, and you expect the custodian to be a machine who has to clean up your mess. You have also forgotten that you are capable of doing things that support others and in this way forget that you are human. Lots of people have been impacted and you have caused harm (a problem). 
At our school, when this happens, we will remember that human beings can repair harm. To help repair the harm, we will bring together people affected by this and let each person tell their story including you by responding to some key questions ... In this way, you will have a chance to understand how to better support and have expectations of others that help them to be human.

This example shows how the Relationship Window keeps educators focused on the relationship and humanity of the people involved rather than the behaviour and the incident. It is a reminder that the people involved are capable and worthy of support, regardless of what has been done. It also reminds educators that, for reparation or healing, all stakeholders are required for dialogue needs. Finally, it clearly illustrates that moving into the TO or FOR quadrants is not an option, as educators would then be objectifying the students they are seeking to support and encourage.

What about the child who refuses to participate, continues to cause harm, or is a significant threat to others? Is it not necessary to then move into an assertive, controlling role? Again the Relationship Window is a reminder that educators are in relationship WITH students, always supporting them, always expecting them to be human. In this way, the Window reminds us to look beyond the incident that has occurred to what it is that prevents the student from trusting us and wait, as Glasser (1985) indicates, until that trust is built. For the well-being of all, the student may need to be removed from the context - not as a punishment, but rather as a means for rebuilding relationship, for gaining trust, for taking time (with necessary support) simply to grow in what it means to be human.

Beyond addressing harm, it is of the utmost importance to see the critical role the Relationship Window plays in being 'the soul of all we do' (Sullivan \& Tifft, 2006). The explanation could continue:

The Relationship Window will also guide how teachers and students learn together. When we teach each other we will remember to support each other and expect each other to be human. What we teach and learn will always be for the purpose of being human not objects. We need to remind each other when we feel 
that what we are learning is not for the well-being of all people. We need to tell each other when we or others feel like machines or toys or dirt while we are learning or teaching.

Here the Window illustrates its impact on curriculum, learning and pedagogy. As a teacher, content is examined through the Relationship Window. Does the story being read reflect healthy relationships? If not, does the lesson allow students to critically reflect on the essence of the story? Does the maths lesson encourage a use of maths skills that will contribute to people being fulfilled or does it idolise profit and economic gain for a few? Does the history unit give voice to marginalised peoples?

Further to this, teaching methods are examined and developed by looking through the Relationship Window. Is a transmissive model of education (Freire, 2000) employed where students take in knowledge simply for the purpose of performing well on tests so that department standards are upheld? Are transformative models of education (Mezirow, 2000) employed which honour the insights and ability of the students so that teachers and students walk with each other, discovering more fully the wonder of this world? Are assessments and evaluations used for adultist purposes that highlight teacher and school quality instead of student growth and well-being? For students, the Relationship Window guides their engagement with content, peers and teachers. Do they recognise what they are learning as significant for how they and others engage with all aspects of this worldpeople and environment? Do they see their responsibility in interacting with teachers and peers as holding potential for supporting and encouraging their humanity?

Extending beyond the school and classroom to the role of administrators, district and national education boards, parents and the community of the educational institution, the Relationship Window also provides a clear foundation for engaging with each other and the educational task at hand. Further to this, the Relationship Window has much to offer proponents of rj involved in other sectors of society as well-a topic for another paper. Ultimately, the Relationship Window challenges all people to engage with ways of being, or philosophies, that are most often assumed. This provides them with a basic value system on which they can rely to discern what nurtures or diminishes life. At a time when many citizens of Western societies are reeling from a post-modern, individual liberalism that has left them untethered and unaware of their potential for harming and being 
harmed, such a grounding in humanisation (Freire, 2000) is welcome. It also provides a way forward in terms of recognising how past indigenous and spiritual traditions can speak to current and future societies.

If there is any doubt that a Window on relationship is necessary, perhaps the insights of Jaron Lanier, Scholar at Large and Partner Architect for Microsoft Research, who pioneered the technology for and coined the term 'virtual reality', can provide a final rationale. In his 2010 book entitled You are not a gadget: a manifesto, he states: 'something started to go wrong with the digital revolution around the turn of the $21 \mathrm{st}$ Century ... A new generation has come of age with a reduced expectation of what a person can be, and who each person might become' (pp. 3-4).

\section{H. Conclusion}

The Social Discipline Window is used globally to educate school personnel and others in the use of rj practices. Presented in this way, the intent is for the Window to identify that rj practices are significant for addressing the emotional and relational needs of students in order to achieve and sustain a healthy civil school culture (McCold \& Wachtel, 2003). In the first decade of its use, changes have taken place as a result of such professional development sessions. However, this article indicates that where educators believe they are moving away from the punitive-permissive paradigm, in reality they may not be or are inconsistent in terms of working restoratively with students.

To address this concern, the design and premise of the Social Discipline Window was examined and found to be a contributor to these misperceptions because of its focus on behaviour instead of relationship. In its stead, a Relationship Window that describes people's engagement with each other as objects or humans is proposed. This Window, which is grounded in the foundational understanding of justice as honouring the worth and working for the well-being of humanity, creates a matrix that has the potential to serve as a clear framework that moves beyond a response to people's behaviour to a means for guiding how people engage with each other and their environments at all times.

As a contribution to the theoretical discussion in the field, the proposed Social Relationship Window is presented for consideration in hopes that it will encourage the 
growth of the critical mass needed to shift to a paradigm that enables people to be who they are meant to be.

\section{References}

Aertsen, I., Parmentier, S., Vanfraechem, I., Walgrave, L. \& Zinsstag, E. (2013). An adventure is taking off. Why restorative justice: an international journal. Restorative Justice: An International Journal, 1(1), 1-14.

Bianchi, H. (1994). Justice as sanctuary. Bloomington, Indiana: Indiana University Press. Braithwaite, J. (1989). Crime, shame and reintegration. New York: Cambridge University Press.

Braithwaite, J. (2006). Doing justice intelligently in civil society. Journal of Social Issues, 62(2), 393-409.

Buber, M. (1958). I and thou (R. Gregory Smith Trans.). Edinburg: T\&T Clark.

Christie, N. (1977). Conflicts as property. British Journal of Criminology, 17(1), 1.

Christie, N. (2013). Words on words. Restorative Justice: An International Journal, 1(1), $15-19$.

Costello, B.; Wachtel, J. \& Wachtel, T. (2010). The restorative practices handbook. Bethlehem, PA: International Institute for Restorative Practices.

Costello, B.; Wachtel, J. \& Wachtel, T. (2012). Restorative circles in schools. Bethlehem, PA: International Institute for Restorative Practices.

Elliott, E. (2011). Security with care. Winnipeg: Ferwood Publishing.

Foucault, M. (1980). Power/knowledge: selected interviews and other writings, 19721977. London: Harvester

Freire, P. (2000). Pedagogy of the oppressed (30th ed.). New York: Continuum.

Gavrielides, T. (2007). Restorative justice theory and practice: addressing the discrepancy. New York: Criminal Justice Press.

Giroux, H. (1988). Teachers as intellectuals: towards a critical pedagogy of learning. Massachusetts: Bergin \& Garvey.

Glaser, D. (1964). The effectiveness of a prison and parole system. New York: BobbsMerrill Company.

Glaser, D. (1969). The effectiveness of a prison and parole system (abridged). New York: 
Bobbs-Merrill Company.

Glasser, W. (1985). Discipline has never been the problem and isn't the problem now. Theory Into Practice, 24(4), 241-246.

Hooks, B. (1994). Teaching to transgress: education as the practice of freedom. New York: Routledge.

Hooks, B. (2003). Teaching community: a pedagogy of hope. New York: Routledge.

IIRP (International Institute of Restorative Practices). (2012). What is restorative practices? Available at www.iirp.org/whatisrp.php.

Ish-Shalom, P. (2009). Theorizing politics, politicizing theory, and the responsibility that runs between. Perspectives on Politics, 7, 303-316.

Johnstone, G. \& Van Ness, D. (eds.) (2007). Handbook of restorative justice. Portland: Willan.

Kincheloe, J. \& McLaren, P. (2005). Rethinking critical theory and qualitative research. In N. Denezin \& Y. Lincoln (eds.), The SAGE handbook of qualitative research (pp. 303-342). Thousand Oaks: SAGE.

Kohn, A. (2005). Unconditional teaching. Educational Leadership, 63(1), 20.

Lanier, J. (2010). You are not a gadget: a manifesto. NewYork: Alfred A. Knopf.

Llewellyn, J. \& Howse, R. (1998). Restorative justice--a conceptual framework. Ottawa: Law Commission of Canada.

Llewellyn, J. (2012). Restorative justice: thinking relationally about justice. In J. Downie \& J. Llewellyn (eds.), Being relational (pp. 89-108). Vancouver: UBC Press.

McCold, P. \& Wachtel, T. (2003). In pursuit of paradigm: a theory of restorative justice. Restorative Practices E-Forum, available at www.iirp.edu/article_detail.php?article_id=NDI0.

Merriam, s (2009). Qualitative research: a guide to design and implementation. San Francisco: Jossey Bass.

Mezirow, J. (2000). Learning as transformation, San Francisco: Jossey Bass.

Morris, R. (1998). Why transformative justice? Paper presented at the ICCPPC World Congress, Mexico City.

Morrison, B. (2012). From social control to social engagement: enabling the time and space' to talk through restorative justice and responsive regulation. In R. Rosenfeld, K. Quinet \& C. Garcia (eds.), Contemporary issues in criminology theory and 
research. Florence, KY: Wadworth.

Morrison, B. (2007). Restoring safe school communities. Sydney: Federation Press.

Morrison, B. \& Ahmed, E. (2006). Restorative justice and civil society: emerging practice, theory, and evidence. Journal of Social Issues, 62(2), 209-215.

Morrison, B., Blood, P. \& Thorsborne, M. (2005). Practicing restorative justice in school communities: the challenge of culture change. Public organization review, 5(4), $335-357$.

Noddings, N. (2005). Caring in education. The encyclopedia of informal education, www.infed.org/biblio/noddings_caring_in_education.htm. (accessed 12 July 2010).

Palmer, P. (1998). The courage to teach. San Francisco: Jossey-Bass.

Patton, M. (2002). Qualitative research \& evaluation methods. Thousand Oaks, CA: Sage Publications.

Pranis, K., Stuart, B. \& Wedge, M. (2003). Peacemaking circles: from crime to community. Minnesota: Living Justice Press.

Pranis, K. (2007). Restorative values. In G. Johnstone, \& D. Van Ness (Eds.), Handbook of Restorative Justice (pp. 59-74). Portland: Willan.

Rawls, J. (1999). A theory of justice (revised edition). Cambridge, Massachusetts: The Belknap Press of Harvard University Press.

Ross, R. (2012). Through a relational lens: rethinking justice conference, Pacific Business and Law Institute, Vancouver, B.C., October 25th \& 26th, 2012, www.youtube.com/watch?v=75HNjefhY3I (accessed 15 July 2013).

Sherman, L. \& Strang, H. (2003). Repairing the harm: victims and restorative justice Utah Law Review, 1, 15-42.

Sherman, L. \& Strang, H. (2007). Restorative justice: the evidence. London: The Smith Institute.

Simon, s (1991). I am loveable and capable. Niles, Il: Values Press.

Steele, B. (2010). Of 'witch's brews' and scholarly communities: the dangers and promise of academic parrhesia. Cambridge Review of International Affairs, 23(1), 49-68.

Sullivan, D. \& Tifft, L. (2005). Restorative justice: healing the foundations of our everyday lives. Monsey, NY: Willow Tree.

Thorsborne, M. \& Vinegrad, D. (2003). Restorative practices in schools: rethinking behaviour management. Queensland: Inyahead Press. 
Vaandering, D. (2009). Towards effective implementation and sustainability of restorative justice in Ontario public schools: a critical case study. $\mathrm{PhD}$. Unpublished dissertation, University of Western Ontario, London.

Vaandering, D. (2011). A faithful compass: rethinking the term justice to find clarity. Contemporary Justice Review, 14(3), 307-328.

Van Manen, M. (2002). The tone of teaching: the language of pedagogy. London, Ont.: Althouse Press.

Viotti, P. and M. Kauppi, (1987). International relations theory. New York: Macmillan Publishing Company.

Wachtel, T. (1999a). Safer Saner Schools: Restoring community in a disconnected world, available at http://www.iirp.org/library/safersanerschools.html.

Wachtel, T. (1999b). Restorative practices in everyday life. Paper presented at: Reshaping Australian Institutions Conference: Restorative Justice and Civil Society, The Australian National University, Canberra, February 16-18, 1999. Retrieved from: http://www.iirp.edu/article_detail.php?article_id=NTAz.

Wachtel, T. (2009). My three decades of using restorative practices with delinquent and at-risk youth: theory, practice and research outcomes. First World Congress on Restorative Juvenile Justice, Lima, Peru, November 5, 2009. Retrieved from: http://www.unicef.org/tdad/2tedwachtel.pdf.

Wachtel, T. (2013). Defining restorative justice. Retrieved from: www.iirp.edu/pdf/DefiningRestorative.pdf.

William Glasser International Institute. (2013). The GQS concept. Retrieved from www.wgii.ie/index.php/about-quality-schools

Williams, R. (1980). The politics of nuclear disarmament. New Left Review, 1(124), 2542.

Wolterstorff, N. (2008). Justice: rights and wrongs. Princeton: Princeton University Press.

Woolford, A. (2009). The politics of restorative justice: a critical introduction. Winnipeg: Fernwood Publishing.

Zehr, H. (2002). The little book of restorative justice. Intercourse, PA: Good Books.

Zehr, H. (1990, 2005). Changing lenses: A new focus for crime and justice (3rd ed.). Waterloo: Herald Press. 
Figures:

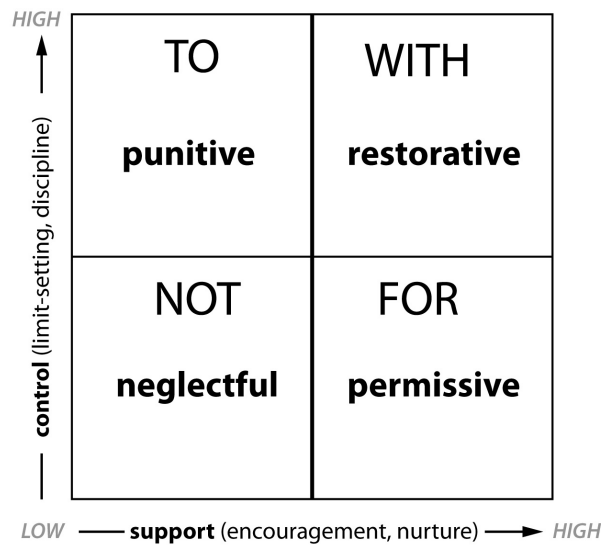

Fig.1 Social Discipline Window (McCold \& Wachtel, 2003)[copyright pending]

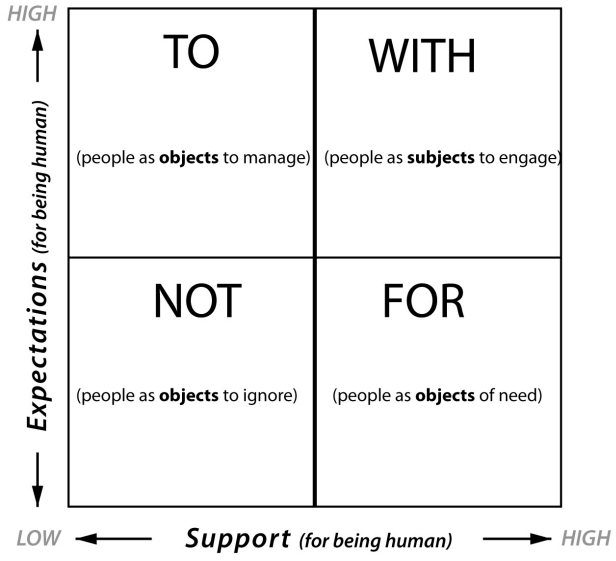

Fig. 2: Relationship Window I

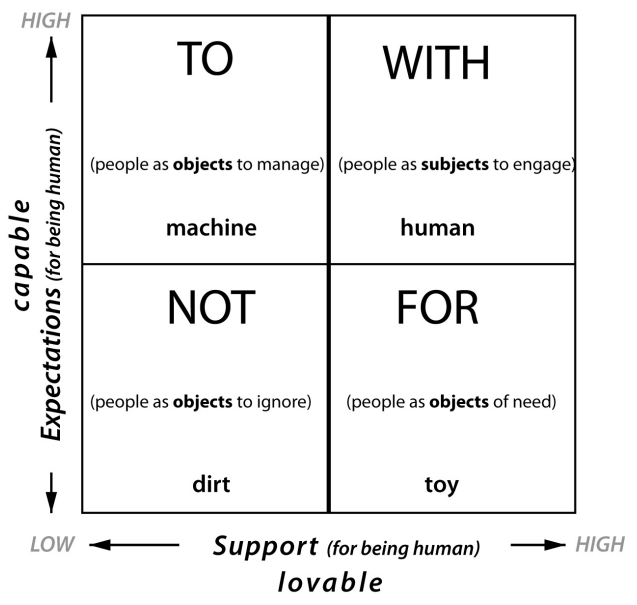

Figure 3: Relationship Window II 


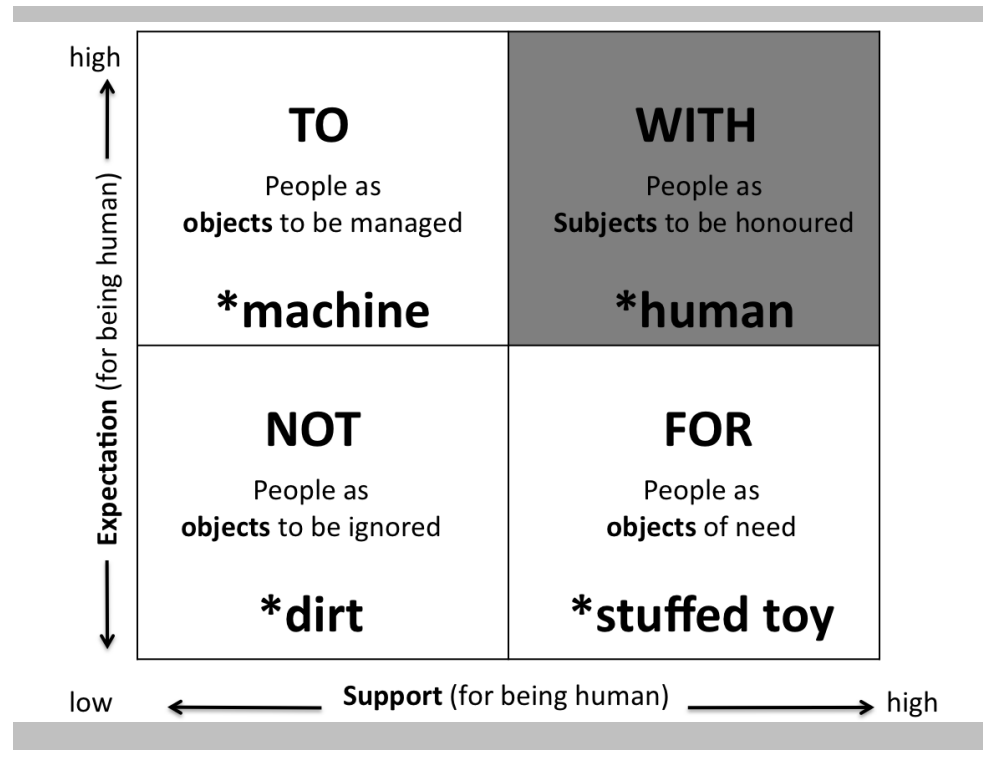

Figure 4: Relationship Window (relationship analogies) 